\title{
DETERMINATION OF LATTICE PARAMETERS BY A SEARCH-SCAN COMPUTER-ASSISTED DATA ANALYSIS METHOD
}
W. E. Baucum
D. A. Carpenter
L. E. Bearden, Jr
K. A. Sells

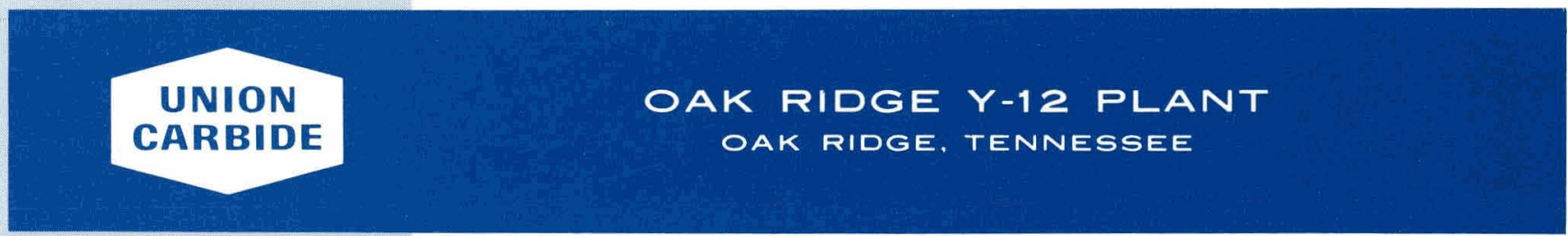




\section{DISCLAIMER}

This report was prepared as an account of work sponsored by an agency of the United States Government. Neither the United States Government nor any agency Thereof, nor any of their employees, makes any warranty, express or implied, or assumes any legal liability or responsibility for the accuracy, completeness, or usefulness of any information, apparatus, product, or process disclosed, or represents that its use would not infringe privately owned rights. Reference herein to any specific commercial product, process, or service by trade name, trademark, manufacturer, or otherwise does not necessarily constitute or imply its endorsement, recommendation, or favoring by the United States Government or any agency thereof. The views and opinions of authors expressed herein do not necessarily state or reflect those of the United States Government or any agency thereof. 


\section{DISCLAIMER}

Portions of this document may be illegible in electronic image products. Images are produced from the best available original document. 
Reference to a company or product name does not imply approval or recommendation of the product by Union Carbide Corporation or the U.S. Atomic Energy Commission to the exclusion of others that may meet specifications.

Printed in the United States of America. Available from

National Technical Information Service

U.S. Department of Commerce

5285 Port Royal Road, Springfield, Virginia 22151

Price: Printed Copy \$4.00; Microfiche \$1.45

This report was prepared as an account of work sponsored by the United States Government. Neither the United States nor the United States Atomic Energy Commission, nor any of their employees, nor any of their contractors, subcontractors, or their employees, makes any warranty, express or implied, or assumes any legal liability or responsibility for the accuracy, completeness or usefulness of any information, apparatus, product or process disclosed, or represents that its use would not infringe privately owned rights. 


\title{
DETERMINATION OF LATTICE PARAMETERS BY A SEARCH-SCAN COMPUTER-ASSISTED DATA ANALYSIS METHOD
}

\author{
W. E. Baucum \\ D. A. Carpenter \\ L. E. Bearden, Jr \\ K. A. Sells \\ Laboratory Development \\ Y.12 Development Division
}

\section{NOTICE}

This report was prepared as an account of work sponsored by the United States Government. Neither the United States nor the United States Atomic Energy Commission, nor any of their employees, nor any of heir contractors, subcontractors, or their employees, makes any warranty, express or implied, or assumes any

egal liability or responsibility for the accuracy, com-

pleteness or usefulness of any information, apparatus,

product or process discinsed, or reprcsents that its use would not infringe privately uwned rights.

Oak Ridge Y-12 Plant

P.O. Box Y. Oak Ridge, Tennessee 37830

Prepared for the U.S. Atomic EnergV Commission Under U.S. . Sinvernmont Contract W.7405 ting-26 


\section{ABSTRACT}

A method has been developed for determining lattice parameters, using a search-scan technique with computer-assisted data analysis. This method consists of collecting $X$-ray diffraction data using a search-scan technique which provides useful data in a digital output format and uses a PDP-15 computer to smooth the data, separate the $K \alpha_{1}$ from the $K \alpha_{2}$ $X$-ray peaks, and find peak locations by fitting a parabola to the top $20 \%$ of the separated $\mathrm{K} \alpha{ }_{1}$ peak. Lattice parameters are then calculated. by a least-squares refinement procedure. This method has reduced operator time and increased analysis precision. 
CONTENTS

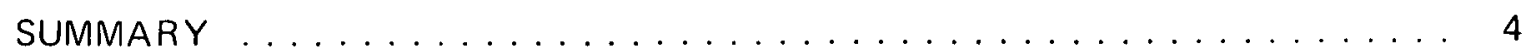

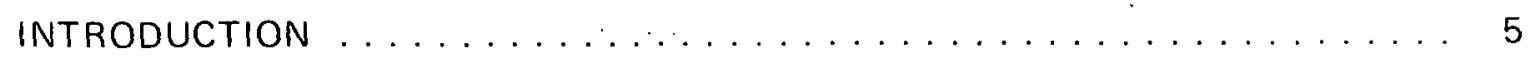

DETERMINING LATTICE PARAMETERS BY A SEARCH-SCAN TECHNIQUE . . . 6

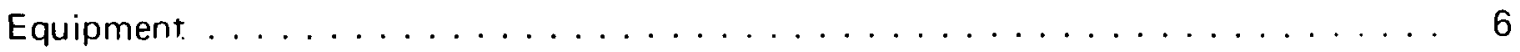

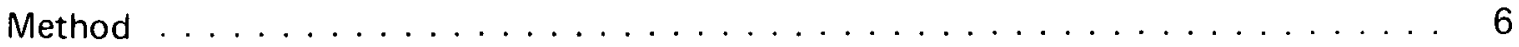

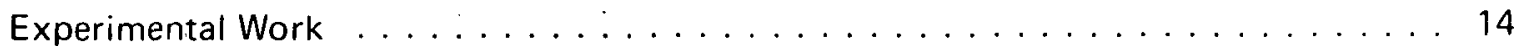

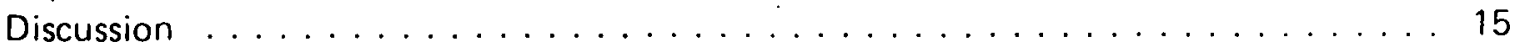

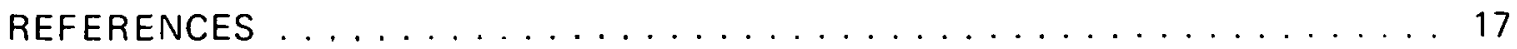




\section{SUMMARY}

A general method has been developed for determining high-precision lattice parameters using a minimum of operator time. The method consists of in-house computer analysis of $X$-ray diffraction data collected in a digital format by a search-scan technique. 


\section{INTRODUCTION}

Lattice parameters are a fundamental material property and, as such, are sensitive to changes in atomic structure. In order to measure lattice parameters, positions of the $X$-ray diffraction lines must be known very precisely. Film methods have traditionally been recognized as giving measurements of line positions which are most free from bias; however, for materials with relatively broad lines, large random errors can result. (1) Diffractometry provides a more reproducible method of measuring line positions because of its superior resolution; but, inherent experimental errors are present ${ }^{(1)}$ which have somewhat limited its use as an absolute method.

Frequently, though, there is more interest in the precise measurement of changes in lattice parameters as a result of changes in atomic structure produced due to some physical process than in determining an absolute value. For example, lattice-parameter changes give valuable information in studies of neutron irradiation damage in materials, ${ }^{(2)}$ determination of phase boundaries of solid solutions, ${ }^{(1)}$ or detection of changes in stoichiometry of materials with variable stoichiometry as in metal carbides or nitrides. (3)

Typically, in diffractometry, lattice parameters are determined from manually measured line positions taken from strip-chart recordings.

In a study of metal carbide lattice parameter changes $(a)$ it was found that the latter method still did not give the required precision. Therefore, in an effort to increase the diffraction line measurement precision, a method was developed for computer analysis of the data collected in a digital format by a search-scan technique. This method will be presented along with a comparision of manual and computer results for a series of metal carbides.

(a) This study was initiated at the Oak Ridge Y-12 Plant which is operated by the Union Carbide Corporation's Nuclear Division for the US Atomic Energy Commission. 


\section{DETERMINING LATTICE PARAMETERS BY A SEARCH-SCAN TECHNIQUE}

\section{EQUIPMENT}

The X-ray generation equipment consisted of a Siemens $60-k \mathrm{~V}$ constant-potential generator with a copper-target high-voltage $X$-ray tube. A Siemens horizontal diffractometer was used to position the sample and detector for proper diffraction.

The data collection equipment consisted of an ORTEC Model 6713 axis controller unit to control the position of the diffractometer and to sample the data, and a scintillation counter, high voltage supply, linear amplifier, pulse-height analyzer, and timer-scaler to detect and count the diffracted $X$ rays. $X$-ray count and counting-time information is outputted through a printout control to a digital cassette tape recorder. The axis controller unit is capable of controlling the diffractometer so as to produce a continuous scan, step scan, or a search scan. The continous scan is a rapid, constant incrementing of the diffractometer with time. Scanning speeds of $1 / 8$ to 36 degrees per minute may be obtained. The step scan is also a constant incrementing of the diffractometer, but the time between increments is preset on the timer and ranges from 0.1 to $10^{6} \mathrm{sec}$. The preset angular increments range from 0.01 to $9.99^{\circ} 20$. The search scan is, a combination of the first two in that the continuous-scan mode is followed until the $X$-ray count (as indicated by a count rate meter) increases above a preset threshold level. At that point, the controller enters the step-scan mode and remains in this mode until the $X$-ray count falls below the threshold value, at which point it returns to the continuous mode. This action premits the controller to "search" for the diffraction peaks at a relatively fast scan rate in the continuous mode and then make a detailed analysis of the peak in the step-scan mode. This procedure generally results in a considerable saving in time, since very little time is spent in the often wide angular range between diffraction peaks.

The data reduction systems consists of a PDP-15/20 computer having $8 \mathrm{~K}$ core memory and the following accessory items: disc, two DECTAPE unlts and two cassette tape urits, paper tape punch and reader, Teletype, high-speed printer, and a Calcomp Model 563 plotter.

\section{METHOD}

Ditfraction data from the sample of Interest are collected using the equipment just described in the search-scan mode of operation. The step increment, counting time, scan speed, ratemeter time constant, starting $2 \theta$, endiny $2 \theta$, threshold value, and diffractometer slits are sclccted according to the expected diffraction characteristics of the semple. After the sample scan, a scan is made of a gold standard peak on both sides of the main beam to determine a constant focal spot misalignment correction to be made to each sample diffraction peak. (4)

The raw data, which are recorded in digital furmal un a tape cassette, are reduced on a PDP-15 computer. Five programs are utilized to reduce the raw data to lattice parameters: (1) data storage program (FILUTL), (2) data smoothing and peak resolution program (RESOL2), (3) plotting program (SPPLTR), (4) peak location program (SPECT2), and (5) lattice parameter refinement program (AMSSML). A flow chart showing the program usage sequence is presented in Figure 1. 


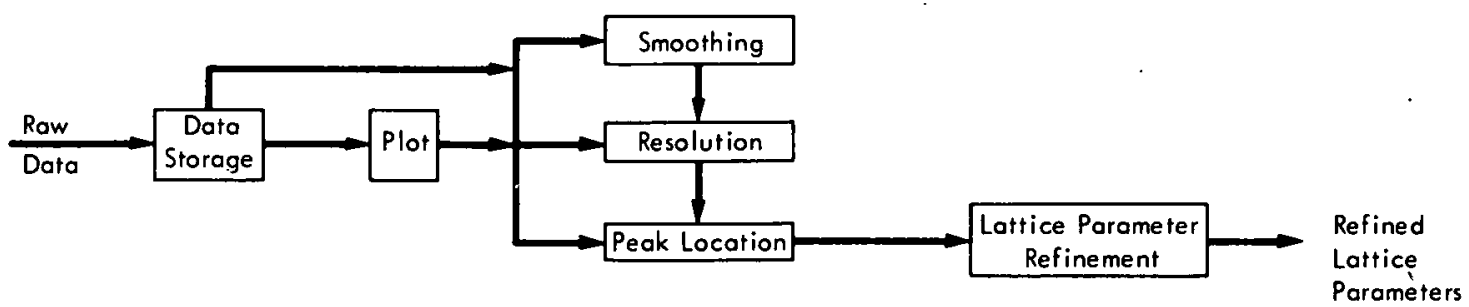

Figure 1. COMPUTER PROGRAM USAGE SEQUENCE.

Data are first transferred from the cassette tape to DECTAPE which can be directly accessed by the computer. A flow diagram of the program, FILUTL, used to accomplish this transfer is given in Figure 2. At this point, an option exists to either go directly into the data reduction programs (if the general characteristics of the data are already known) or first plot the data to determine their characteristics and then enter the reduction programs. The plotting program uses a set of library callable routines $(5)$ to plot $X$-ray counts on the $Y$ axis versus diffraction angle on the $X$ axis. Both $X$ and $Y$-axis scale factors may be adjusted according to the particular interest of the user; thus, if the user wishes to see small detail, the plot may be blown up; or, if the interest is in the overall characteristics, it may be shrunk. Since the $X$ axis will have points of discontinuity when using the search-scan mode, the new diffraction angle is printed at each point of discontinuity (Figure 3 ).

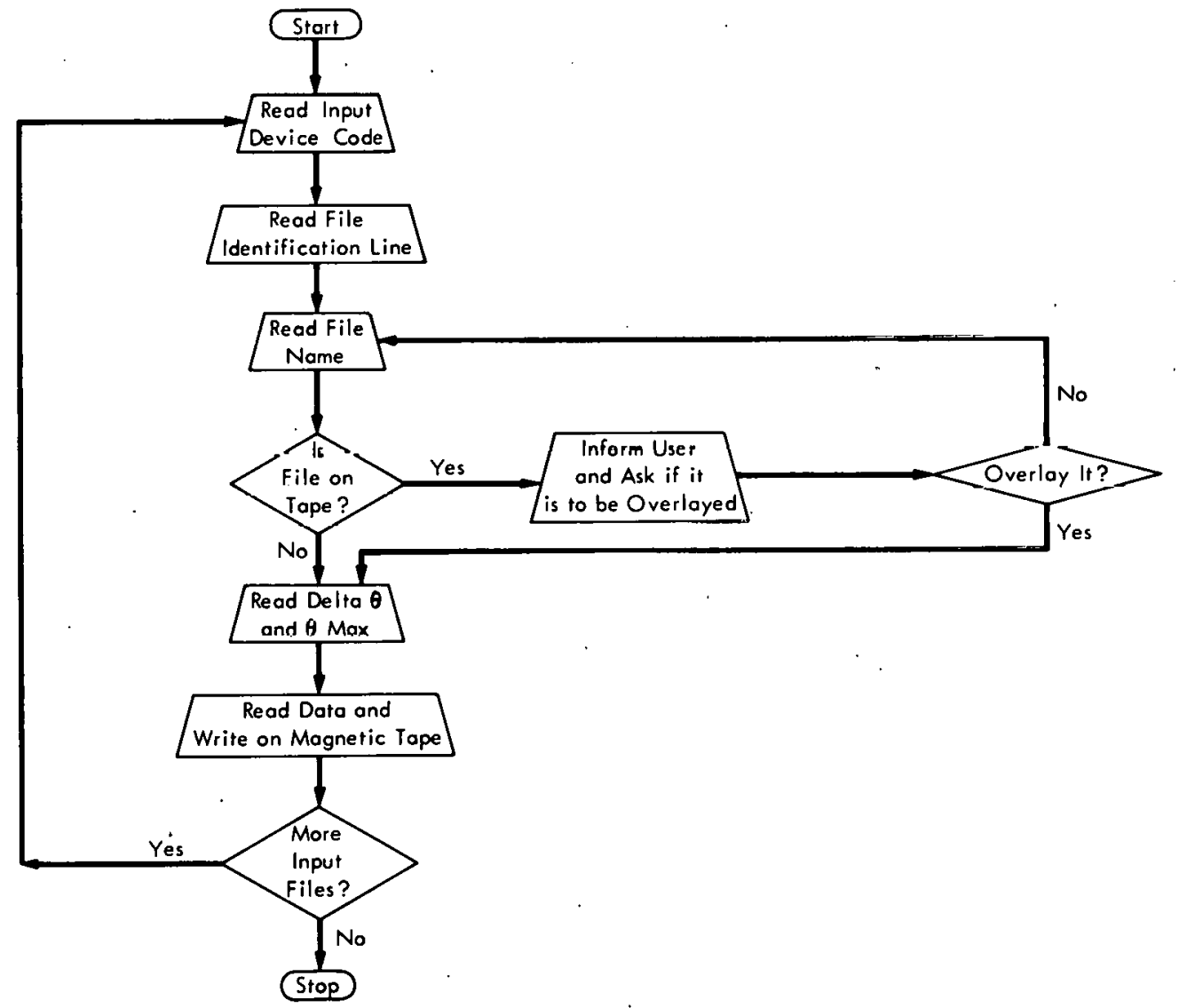

· Figure 2. FILUTL PROGRAM FLOW DIAGRAM. 


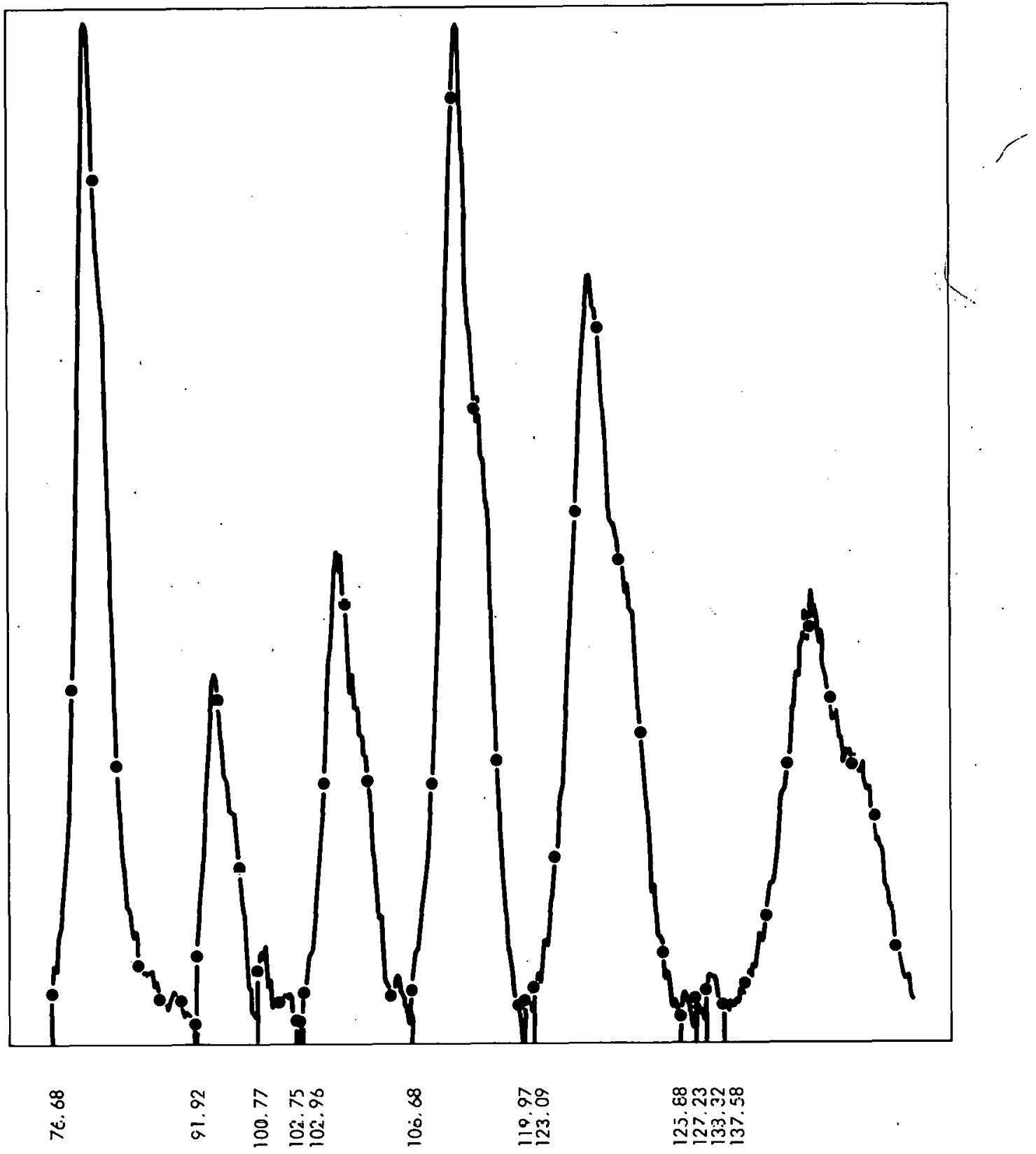

Figure 3. SĖARCh-SCAN DATA fROM SAMPLE S-0-9 (TiC). (A Circle is Plotted at Every Ten Points)

If the raw data contain a relatively large percentage of statistical error, the smoothing program may be used to make it more amenable to resolution or peak location. The program uses a linear weighted average technique in which the intensity value at a particular diffraction angle is determined by doubling the raw intensity at that point, adding in the intensities of two points on both sides, and dividing by six. Thus, the smoothed data retain the characteristics of the raw data but have smaller fluctuations (Figure 4).

If plots of raw data showed a partial resolution of the $\alpha_{1}$ and $\alpha_{2}$ doublet, removal of the $\alpha_{2}$ peak may be accomplished using the resolution program. This program uses the standard 


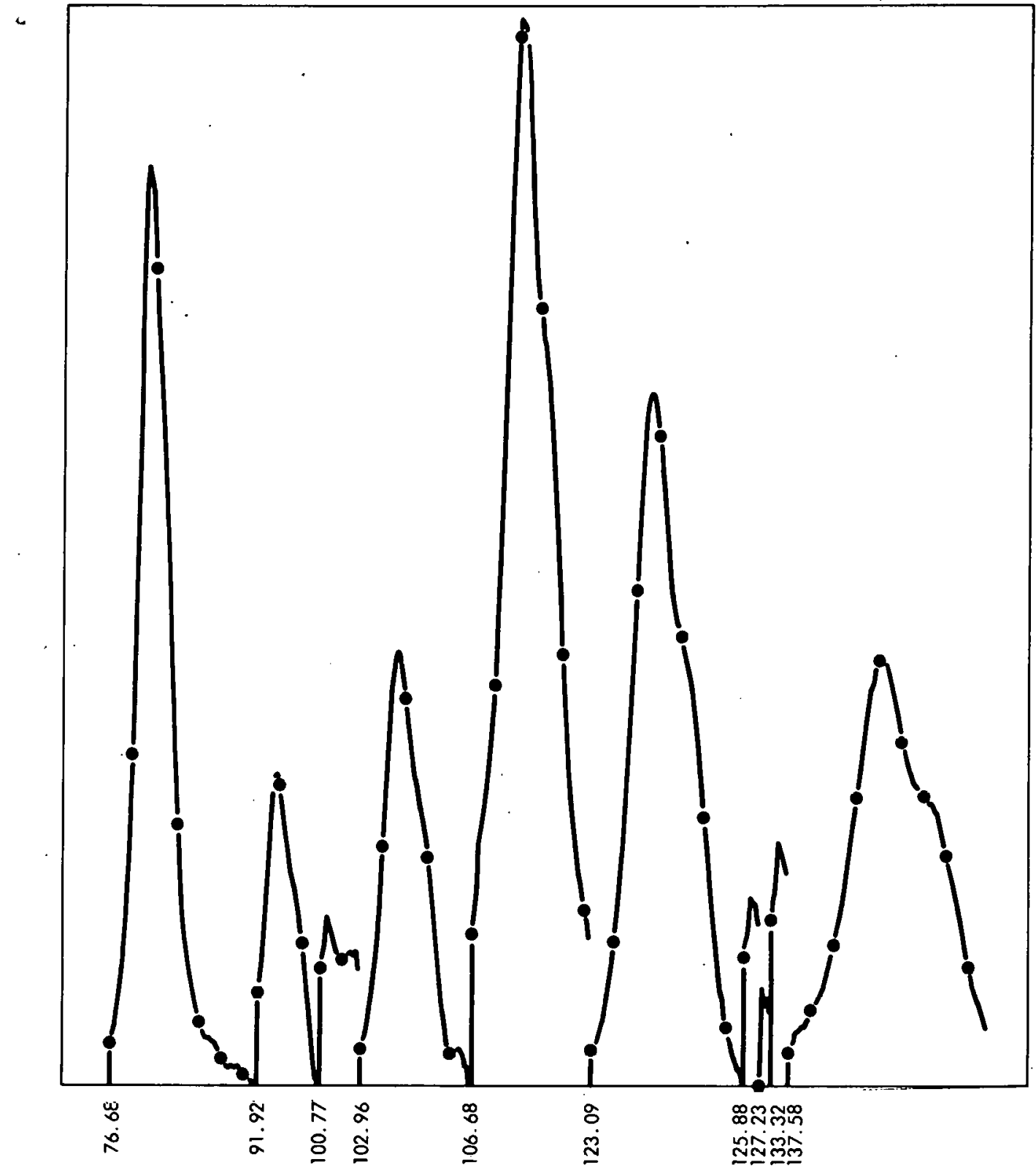

Figure 4. SEARCh-SCAN DATA FROM SAMPLE S-0.9 (TiC) AFTER SMOOTHING. (A Circle is Plotted at Ẹvery Ten Points)

Rachinger separation technique ${ }^{(6)}$ and directs the computer to first calculate the theoretical separation, $\Delta$, of the two peaks using the equation:

$$
\frac{\sin \theta}{\lambda_{1}}=\frac{\sin (\theta+1 / 2 \Delta)}{\lambda_{2}}
$$

where:

$\theta$ represents the Bragg angle of the maximum intensity in the profile (the approximate $K \alpha_{1}$, peak position) 
$\lambda_{1}$ the wavelength of the $K \alpha_{1}$ radiation, and

$\lambda_{2}$ the wavelength of the $K \alpha_{2}$ radiation,

or:

$$
1 / 2 \wedge=\sin ^{-1}\left[\left(\lambda_{2} / \lambda_{1}\right) \sin \theta\right]-\theta
$$

Knowing the value of $\Delta$ and assuming that the intensity of the $\alpha_{2}$ peak is $1 / 2$ that of $\alpha_{1}$ gives:

where:

$$
\mathrm{I}_{\mathrm{j}}\left(\alpha_{1}\right)=\mathrm{I}_{\mathrm{j}}-\mathrm{I}_{\mathrm{j}} / 2-\Delta\left(\alpha_{1}\right)
$$

$\mathrm{I}_{i}\left(\alpha_{1}\right)$ represents the intensity from the $\alpha_{1}$ peak, and

$I_{i} \quad$ the intensity from the $\alpha_{1}-\alpha_{2}$ doublet from raw data.

Thus, the $\alpha_{2}$ peak is substracted out leaving only the $\alpha_{1}$ peak arising from a known wavelength which is necessary for lattice parameter calculations. An example of the effect of both the smoothing and resolution programs is given in Figures 3, 4, and 5. Also, a flow diagram of the two programs is presented (Figure 6).

Precise lattice parameters require the precise location of diffraction peaks which is the purpose of the peak location program. A flow diagram of the program is given in Figure 7. The program directs the computer to scan the entire diffraction data looking for slope changes which indicate the presence of peaks. To discriminate between random intensity fluctuations and actual peaks, the program requires that the slope change be consistent over four successive intensity points in order to Indicate a peak. After finding all peaks, the computer least-squares fits a parabola to the upper $20 \%$ of each peak, which normally approximates a parabola, $(1)$ and calculates the center of the parabola by:

$$
a x^{2}+b x+c=y
$$

and, at a maxima:

$$
\frac{d y}{d x}=2 a x+b=0
$$

so:

$$
x_{\text {peak }}=-b / 2 a
$$

The computer outputs the located peaks, their intensities, and their probable errors obtained from the least-squares fit, and then enters an EDIT mode. At this point, the operator has the option to either assign HKL values to the true peaks and delete false ones (this decision is made by studying the intensity, probable error, and a plot of data if available), or he may input a paper tape containing the allowed HKL values and their 


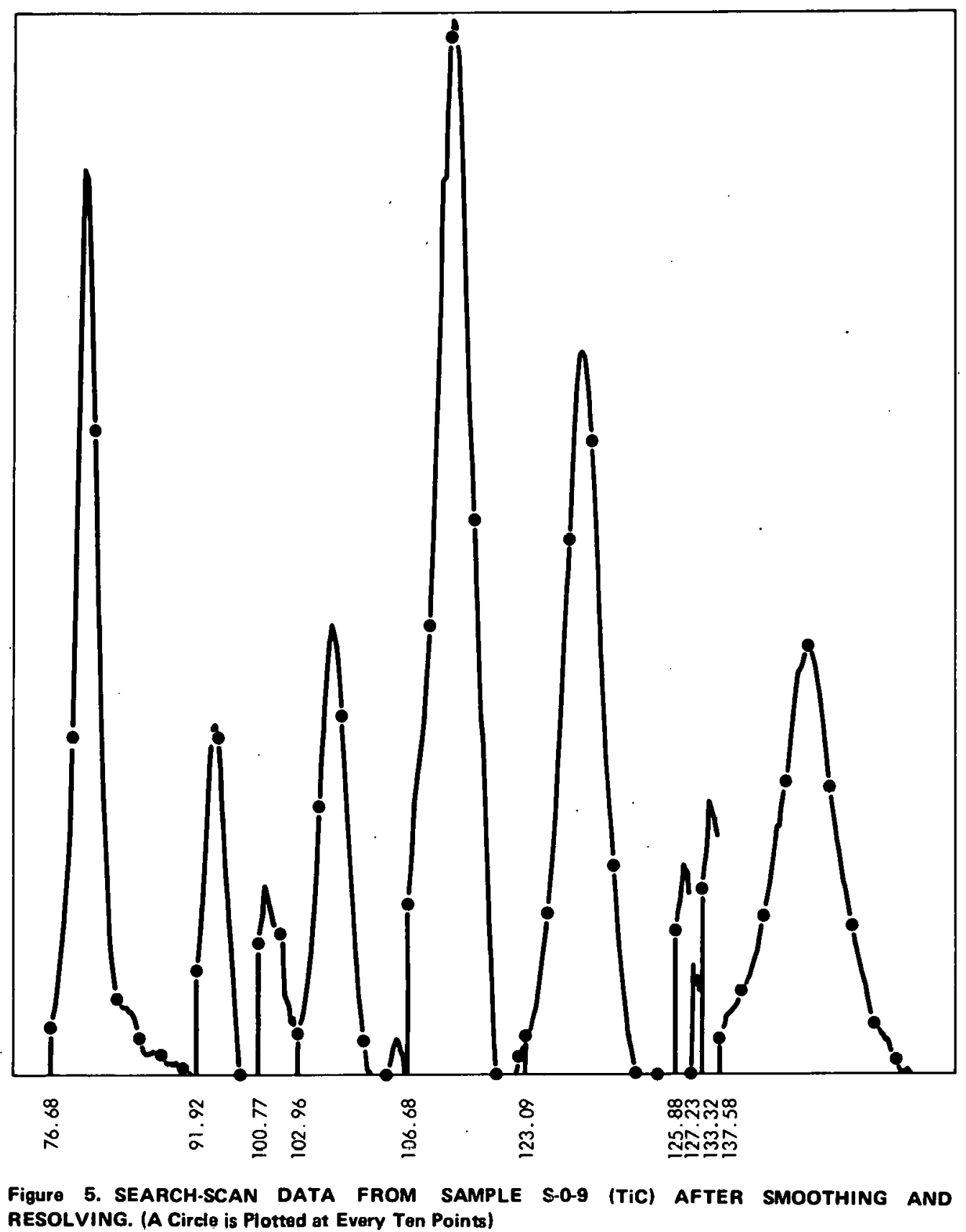

associated angles for the known structure which the computer will compare to its located peaks and assign HKL values automatically. Upon completion of the editing, the computer asks for constants necessary for the lattice parameter refinement program such as lattice structure type, initial lattice parameters, and refinement code, which are entered by paper tape. Next, the computer asks for a theta correction (determined earlier by scanning the gold standard) which is subtracted from each calculated peak position. At this point, all data are outputted on paper tape in the proper format to be used in the lattice parameter refinement program. 


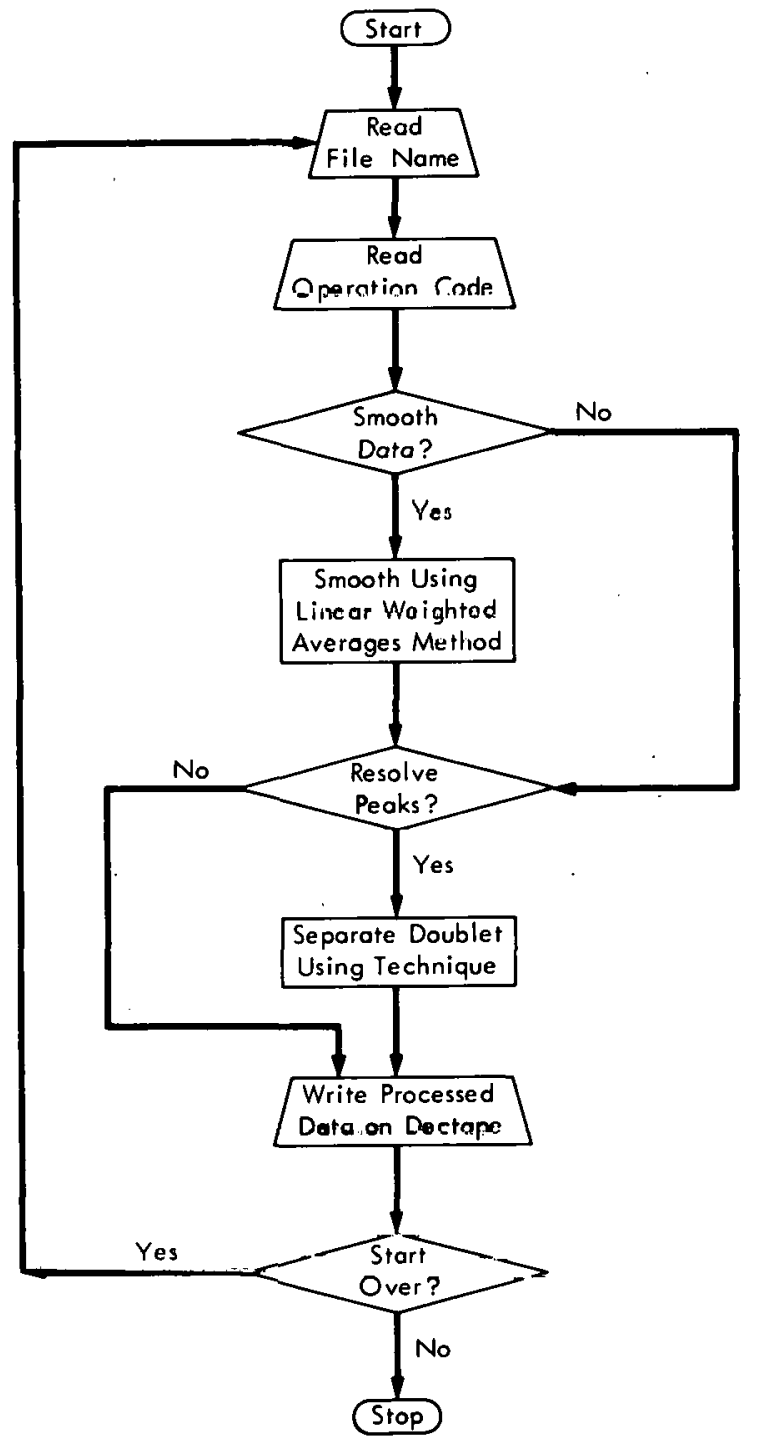

Figure 6. RESOLZ PROGRAM FLOW DIAGRAM.

The purpose of the lattice parameter refinement program is to further refine the data by correcting for errors in sample alignment and to find lattice parameters which best fit the data obtained througlı all programs up to thls puint. Using a program by Williams, $(7)$ modified to run on a PDP-15, it is possible to refine $a, b, c, \alpha, \beta$, and $\gamma$ for all possible lattice structures. The program directs the computer to least-squares fit a straight line to the input data using one of four available extrapolation functions, depending on the diffraction geometry used, and to extrapolate to $180^{\circ} 2 \theta$ and find the values of the lattice parameters which best fit the input data. The program automatically cycles the data until the change in parameter value between two successive cycles is insignificant. After each cycle, the computer writes out on a high-speed printer the change in parameters, the value of the parameter, and the estimated standard deviation of the least-squares fit. After the final iterative reduction in $\sigma$, the computer writes a variance-covariance matrix, a correlation 
matrix, a table showing indices, observed $2 \theta$, calculated $2 \theta$, estimated error, observed minus calculated $2 \theta$, calculated drift, and $\lambda$ used for each diffraction peak (Figure 8 ).

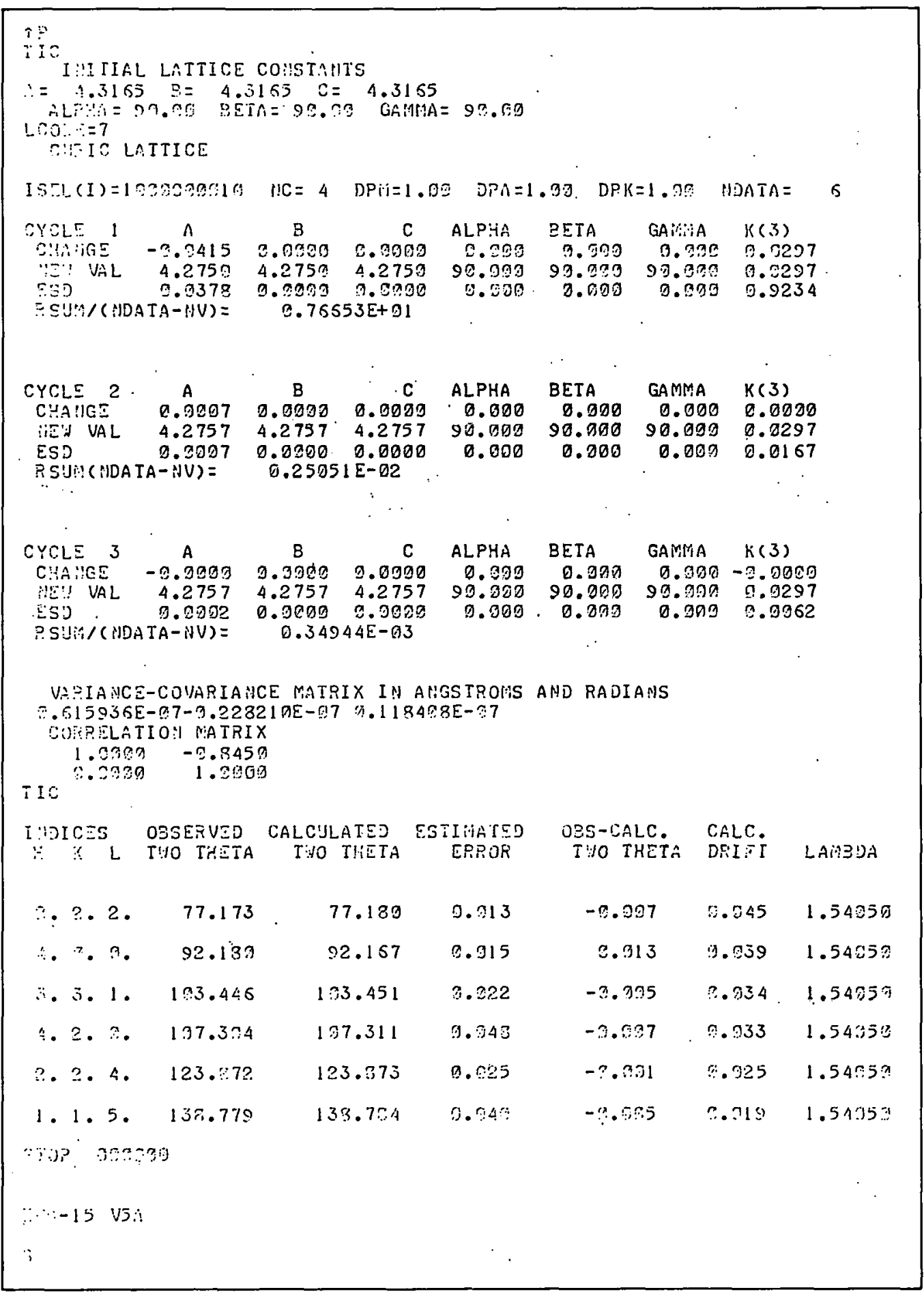

Figure 8. COMPUTER PRINTOUT OF LATTICE PARAMETER CALCULATION FROM LCR-2 ON SAMPLE S-0-9 (TIC) AFTER COMPUTER ANALYSIS OF THE DATA. 


\section{EXPERIMENTAL WORK}

Lattice parameters of samples of titanium carbide $(\mathrm{TiC})$ and niobium carbide ( $\mathrm{NbC})$ were determined as part of a study of the effects of various heat treatments on mixtures of these carbides with carbon. Table 1 gives lattice parameters determined by the computer technique compared with those determined by manually measuring the midpoints of the diffraction peaks at $80 \%$ maximum intenslty.

The NhC samples in the computer column were search scanned with a scanning speed of $1 \% / \mathrm{min}$, ratemeter range of $2 \times 10^{2} \mathrm{c} / \mathrm{sec}$, time constant of $3 \mathrm{sec}$, step size of $0.03^{\circ}$. and counting time of $80 \mathrm{sec}$. A $0.1-\mathrm{mm}$ detector slit was used along with a graphite diffracted beam monochromator. For all of the samples in this study, the monochromator was adjusted so that the $K \alpha_{1}$ peaks were twice the intensity of the $K \alpha_{2}$ peaks in order to facilitate the use of the peak resolution program. The search-scan threshold was set on the low-angle background of the $\mathrm{NbC}(400)$ peak. The lattice parameter refinement, using LCR-2,(7) included the (400), (331), (120), (122), (511), and (440) peaks of $\mathrm{NbC}$.

The same NbC samples were scanned continuously on a strip-chart recorder at $1 / 8 \%$ min in both the forward and reverse directions. Peak positions were determined by manually measuring the midpoints of the resolved profiles at $80 \%$ maximum intensity and then averaging the forward and reverse scans. The lattice parameter refinement was carried out using LCR-2 with the same NbC peaks as listed in the preceding paragraph. The resulting lattice parameters are given in the "manual" column of Table 1.

Data for the TIC samples were collected before the search-scan technique was available. Each peak was step scanned $\left(0.05^{\circ}\right.$ step, 40-second count) and the data collected on paper tape. The data were plotted and peak locations determined by manually measuring the midpoints of the $K \alpha_{1}, K \alpha_{2}$ profile at half maximum intensity. The lattice parameter refinements were carried out using LCR-2(7) with the (222), (400), (331), (420), (224), and (115) TiC peaks included in the refinement. The resulting lattice parameters are listed in the "manual" column of Table 1. The same data were later treated by computer analysis, and these lattice parameters are listed in the "computer" column of Table 1. One sample, S-0-9, was search scanned using the same parameters as for $\mathrm{NbC}$. 
The lattice parameter of a $\mathrm{NbC}$ sample (S-0-15) was also determined from data collected with a Debye-Scherrer camera. The result is included in Table 1 for comparison with the diffractometer values.

\section{DISCUSSION}

One object of the carbide study was to determine whether differences occur among samples within each sample group. Lower standard deviations $(\sigma)$ mean that smaller differences may be discerned. Comparison of the $\sigma$ s listed in Table 1 show $\sigma$ to be lower in almost all cases for the computer-assisted data than for the manual data. In addition, a significant operator time savings was realized using the search-scan computer-assisted method over the manual method for $\mathrm{NbC}$. Each sample required approximately 30 minutes of operator time compared with approximately 185 minutes for the manual method. The 30 minutes includes about 20 minutes computing time which can be further reduced. The computer used has only limited core memory $(8 \mathrm{~K})$ and this necessitates the use of magnetic tape for data storage. Additional core memory for data storage could reduce the computing time considerably.

The TiC data provide the opportunity to compare the results of manual data analysis with computer analysis since the same data were used for both analyses. The relatively large $\sigma$ s in the "manual" column are caused primarily by the inability of the operator to obtain diffraction peak locations as reproducibly as the computer.

In general, $\sigma$ in the "computer" column decreases through each sample group from the lowest sample number to the highest because the concentration of the metal carbide in carbon increases within each group with increasing sample number. The lower concentrations have lower count rates which cause higher random errors in the parabola fit to the individual peaks. The $\mathrm{NbC}$ standard deviations are lower than those of the TiC samples because the $\mathrm{NbC}$ concentrations are higher than the TiC samples, more peaks at higher diffraction angles were used for $\mathrm{NbC}$ than for $\mathrm{TiC}$, longer counting times and a shorter stepping interval were used for $\mathrm{NbC}$ than for $\mathrm{TiC}$, and the TiC peaks were much broader than the $\mathrm{NbC}$ peaks. The $\mathrm{NbC}$ standard deviations probably represent a lower limit (in the absence of temperature control) since a change of one degree centigrade would result in a cliange of approximately $3 \times 10^{-5} \mathrm{~A}$ in the lattice parameter of $\mathrm{NbC}$. (3)

The lower standard deviations given by computer analysis allow more valid comparisons to be made when checking for differences among lattice parameters. The apparent variations observed within some of the sample groups after manual analysis of the TiC data largely disappeared after computer analysis, although differences observed in the 3-0 sample group are apparently real.

The method deseribed in this repurt is more flexible than more automated methods in that interaction between the operator and the computer permits any type of sample to be analyzed. The operator is free to include or exclude any peaks in the pattern in the final refinement. For example, in low-symmetry materials, the operator may wish to exclude overlapping peaks. The operator may also exclude peaks from other phases. This action may be accomplished in the EDIT mode after either the peak search program or the lattice parameter refinement program. Use of a more automated data collection mode, such as the 
one described by Kelly and Short, $(8)$ is possible. However, with search scanning more versatility is added by the fact that data for all of the peaks in the scan range are collected so that if any phases are present other than the phase of interest, they can be detected in the plotted data or peak location output.

Accuracy of the lattice parameters obtained by the method described in this report is comparable to that given by a Debye-Scherrer camera which is shown by a comparison of the results obtained by the diffractometer method with that given by the Debye-Scherrer camera for the NbC Sample S-8-15 (Table 1). The apparent difference between the two lattice parameters is not statistically significant. 


\section{REFERENCES}

(1) Cullity, B. D.; Elements of X-Ray Diffraction; Addison-Wesley Publishing Company, Incorporated, Reading, Massachusetts (1956).

(2) Billington, D. S. and Crawford, J. H., Jr; Radiation Damage in Solids; Princeton University Press, Princeton, New Jersey (1961).

(3) Toth, L. E.; Transition Metal Carbides and Nitrides, p 6; Academic Press, New York (1971).

(4) King, H. W. and Vassamillet, L. F.; "Precision Lattice Parameter Determination by Double-Scanning Diffractometry", Advances in X-Ray Analysis, 5, pp 78-85; Plenum Press, New York (1961).

(5) Plotter Output Routines for the PDP-15 Advanced Software System; Digital Equipment Computer Users Society, DECUS 15-39, Haynard, Massachusetts; February 14, 1972.

(6) Rachinger, W. A.; Journal of Scientific Instruments, 25, p 254 (1948).

(7) Williams, D. E.; LCR-2, A Fortran Lattice Constant Refinement Program, USAEC Report TID-4500; October 1, 1964.

(8) Kelly, C. J. and Short, M. A.; Advances in X-Ray Analysis, 15, Edited by K. F. J. Heinrich, et al, pp 102 - 113; Plenum Press, New York (1972). 


\section{DISTRIBUTION}

Atomic Energy Commission - Oak Ridge

Hickman, H. D.

Zachry, D. S., Jr

Oak Ridge Gaseous Diffusion Plant

Wilcox, W. J., Jr

Winkel, R. A.

Oak Ridge Y-12 Plant

Ammons, A. M.

Baucum, W. E. (5)

Bearden, L. E., Jr

Briscoe, O. W.

Burditt, R. B.

Burkhart, L. E.

Carpenter, D. A.

Cooper, R. H.

Denny, A.

Duerkson, W. K.

Ebert, T. H.

Fraser, R. J.

Hulsey, W. J.

Johnson, D. H.

Keith, A.

Kite, H: T.

Lundin, M. I.

McLendon, J. D.

Phillips, L. R.

Pollock, C. B.

Rowan, J. H.

Schreyer, J. M.

Sells, K. A.

Smith, R. D.

Weathersby, W. E.

Yaggi, W. J./Gongin, J. M.

$Y$-12 Central Files (5)

$Y-12$ Central Files (master copy)

$Y-12$ Central Files (route copy)

$Y-12$ Central Files (Y-12RC)
Paducah Gaseous Diffusion Plant

Levin, R. W.

Sandia - Albuquerque

Mullendore, A. W.

In addition, this report is distributed in accordance with the category UC-4, Chemistry, as given in the USAEC Standard Distribution Lists for Unclassified Scientific and Technical Reports, TID-4500. 